\title{
Infrared Matrix Spectra of Lithium Fluoride
}

\author{
Stanley Abramowitz and Nicolo Acquista \\ Institute for Basic Standards, National Bureau of Standards, Washington, D.C. 20234 \\ and \\ Ira W. Levin \\ National Institute of Arthritis and Metabolic Diseases, National Institutes of Health, \\ Bethesda, Maryland 20014
}

(June 19, 1968)

\begin{abstract}
Evidence for a linear dimer $\mathrm{Li}_{2} \mathrm{~F}_{2}$ has been obtained by extending the spectral measurements for matrix isolated lithium fluoride into the far infrared region. The vapors from solid ${ }^{6} \mathrm{LiF},{ }^{7} \mathrm{LiF}$, and ${ }^{6} \mathrm{LiF} /{ }^{7} \mathrm{LiF}$ mixtures were deposited in argon matrices at liquid hydrogen temperatures. Vibrational assignments were made on the basis of the following linear species: ${ }^{6} \mathrm{Li}_{2} \mathrm{~F}_{2},{ }^{7} \mathrm{Li}_{2} \mathrm{~F}_{2},{ }^{6}{ }^{7} \mathrm{Li}_{2} \mathrm{~F}_{2}$ and ${ }^{7},{ }^{6} \mathrm{Li}_{2} \mathrm{~F}_{2}$. Although the specific geometry of the dimer could not be determined, a normal coordinate analysis supported the spectral interpretation of a linear structure $\left(C_{\infty v}\right)$
\end{abstract}

Key Words: Force field; infrared; lithium fluoride dimer; low temperature; matrix; vibrational assignment.

\section{Introduction}

Infrared spectra of matrix isolated lithium fluoride species indicate the formation of a rhomboid dimer of $D_{2 h}$ symmetry in addition to the monomeric form [1-5]. ${ }^{1}$ Several prominent spectral features, however, are not satisfactorily assigned to a specific LiF system, in particular, the sets of relatively strong bands that occur in argon matrices at 722 and $495 \mathrm{~cm}^{-1}$ and at 769 and $522 \mathrm{~cm}^{-1}$ for the isolated vapors of ${ }^{7} \mathrm{LiF}$ and ${ }^{6} \mathrm{LiF}$, respectively. Since the matrix absorption bands for the two isotopic forms of the monomer appear at 842 and $888 \mathrm{~cm}^{-1}$, some workers attribute the additional bands to monomeric $\mathrm{LiF}$ absorptions arising from supplementary matrix trapping sites [1, 2]. Alternatively, other investigators believe that the unassigned bands may be due to the formation of either a trimer or higher polymeric species $[3,6]$. Reddington, however, suggests that the controversial features possibly reflect the two high frequency stretching modes of a matrix stabilized linear dimer [5].

In the present study the infrared measurements on matrix isolated lithium fluoride are extended into the far infrared region. Since the spectrum exhibits

\footnotetext{
1 Figures in brackets indicate the literature references at the end of this paper.
}

absorption features from several species, carefully controlled matrix diffusion experiments in conjunction with double boiler techniques for producing the gaseous molecules allowed the absorption bands of a given molecular type to be grouped together. Spectra from isotopic molecules, as well as mixtures of varying isotopic compositions, aided both the grouping and assignment of the vibrational features. One group of bands which occur in the $700 \mathrm{~cm}^{-1}, 500 \mathrm{~cm}^{-1}$, and far infrared regions are interpreted as absorptions of a linear dimer with two nonequivalent lithium atoms. Other simple interpretations for these features, such as supplementary trapping sites or a cyclic trimer, are considered and found to be inconsistent with the sum of data observed.

\section{Experimental}

The methods used to isolate high temperature species in rare gas matrices have been described in detail elsewhere [7]. Depending upon the spectral region studied, the infrared spectra were obtained either with a Perkin-Elmer model 99G monochromator or a Perkin-Elmer model 301 spectrophotometer [8]. An Air Products Cryotip supplied the refrigeration at liquid hydrogen temperatures and provided the 
necessary controlled temperature regulation from 20 to $33 \mathrm{~K}$, while an electron bombardment furnace vaporized the $\mathrm{LiF}$ samples. ${ }^{7} \mathrm{LiF}$ and ${ }^{7} \mathrm{LiF}$ samples; supplied by the Stable Isotopes Division, Oak Ridge National Laboratory, were evaporated in double oven crucibles and were deposited in an argon matrix on thin CsI windows. These samples, as well as isotopic mixtures, were investigated in the region from 1000 to $150 \mathrm{~cm}^{-1}$.

The narrow absorption bands of the same species will either increase or lose intensity at the same rate upon controlled diffusion at temperatures above $20 \mathrm{~K}$, thus providing a convenient method of identifying groups of bands with a particular molecular species. Mole ratios of the species in the vapor are altered by raising the temperature of the gas effusing from the Knudsen cell; therefore, one can assign bands to the same species by their relative decrease in intensity relative to the $\mathrm{LiF}$ monomer. Enriched samples of ${ }^{6} \mathrm{LiF}$ containing 95 percent ${ }^{6} \mathrm{LiF}$ and 5 percent ${ }^{7} \mathrm{LiF}$ were utilized in addition to ${ }^{\mathrm{n}} \mathrm{LiF}$ which has about 95 percent ${ }^{7} \mathrm{LiF}$ and 5 percent ${ }^{6} \mathrm{LiF}$. Additional information was obtained by examining the spectrum of thick deposits of ${ }^{7} \mathrm{LiF}$ in the region of the ${ }^{6} \mathrm{LiF}$ absorptions and vice versa. The difficulties in estimating both the temperature of the effusing gas and the ratio of the matrix diluent to the sample (M/S) have been discussed $[1,2,5,7]$. M/S ratios of $500: 1$ to $1000: 1$, and temperatures from $850{ }^{\circ} \mathrm{C}$ to $1200{ }^{\circ} \mathrm{C}$ are representative of the conditions used in these experiments.

Internal and external absorption standards were used to calibrate the observed spectra. Spectral slit widths of about $0.5 \mathrm{~cm}^{-1}$ and $1.0 \mathrm{~cm}^{-1}$ were employed in the region from 1000 to $400 \mathrm{~cm}^{-1}$ and from $400-150$ $\mathrm{cm}^{-1}$, respectively.

\section{Experimental Results}

Classifying the sets of bands of the various species by controlled diffusion experiments and double boiler observations yields the following groups: (1) monomeric bands of $\mathrm{LiF}$ at $835 \mathrm{~cm}^{-1}$ for ${ }^{7} \mathrm{LiF}$ and $888 \mathrm{~cm}^{-1}$ for ${ }^{6} \mathrm{LiF}$; (2) bands due to the cyclic dimer of ${ }^{7} \mathrm{Li}_{2} \mathrm{~F}_{2}$, ${ }^{6} \mathrm{Li}_{2} \mathrm{~F}_{2}$ and ${ }^{6} \mathrm{Li}^{7} \mathrm{LiF}_{2}$; (3) bands at 767.8, 518.6, 270.2, 261.0 and $157.1 \mathrm{~cm}^{-1}$ for ${ }^{6} \mathrm{LiF}$ and at 720.5, 497.5, 255.2, 245.7, and $152.8 \mathrm{~cm}^{-1}$ for ${ }^{7} \mathrm{LiF}$; (4) all other bands in the spectrum which increased in intensity relative to the monomer during diffusion experiments at temperatures above $20 \mathrm{~K}$ (and also are significantly lower in intensity relative to the monomeric species when the temperature of the effusing gas is raised). The behavior of the fourth group of bands indicate that they originate from polymeric species containing more lithium atoms than the species responsible for the other absorption bands in the spectrum.

Upon controlled diffusion at temperatures up to $33 \mathrm{~K}$, the group 2 bands decreased in intensity relative to the monomer at a significantly more rapid rate than the group 3 bands. The group 3 bands decreased in intensity at a somewhat greater rate than the monomeric bands, while the group 4 bands all increased in intensity. At elevated temperatures of effusion both group 2 and 3 bands were reduced in intensity relative to the monomer with the diminution in group 2 greater than that in group 3. As we already indicated, the group 4 bands were decreased in relative intensity to a greater extent than both groups 2 and 3 .

The relative intensity of all features compared to the monomeric species was only a function of the temperature of the effusing vapor. Flow rates were varied over the range of 0.05 to $0.20 \mathrm{mmol} / \mathrm{min}$ of argon without observing any change in the spectrum. This precludes any explanation of the five bands in group 2 based upon supplementary trapping sites in the matrix for the monomeric species. Also, it is unlikely that an argon matrix could perturb the vibrational fiequency of a monomeric lithium fluoride to cause the large observed matrix shifts. The details of the five absorption bands belonging to group 3 which, again, because of their behavior and isotopic splitting patterns, belong to the same molecular species, will now be discussed in detail with particular emphasis directed towards assigning these bands to a linear dimer with two nonequivalent lithium atoms. In a later section a discussion of other possibilities will be included.

\subsection{The $400-150 \mathrm{~cm}^{-1}$ Region}

The observed infrared spectra of matrix isolated ${ }^{7} \mathrm{LiF},{ }^{6} \mathrm{LiF}$, and a $1: 1$ mixture of ${ }^{7} \mathrm{LiF} /{ }^{6} \mathrm{LiF}$ appear in figure la for the $240-300 \mathrm{~cm}^{-1}$ region. The strong features at 293.8 and $276.4 \mathrm{~cm}^{-1}$ in ${ }^{6} \mathrm{LiF}$ and ${ }^{7} \mathrm{LiF}$ are assigned to the lowest infrared active vibration $\nu_{4}$ of the planar rhomboid dimer of LiF. Confirmation is given by the triad at $293.8,284.7$, and $276.4 \mathrm{~cm}^{-1}$ for the $1: 1$ mixture of ${ }^{7} \mathrm{LiF} /{ }^{6} \mathrm{LiF}$, since the observed relative intensities of $1: 2: 1$ are those expected for a dimer with equivalent lithium atoms. (A sample containing equal part of ${ }^{6} \mathrm{LiF}$ and ${ }^{7} \mathrm{LiF}$ would be expected to exhibit bands of relative intensity of $1: 2: 1$ and $1: 1: 1: 1$ for the cases of a dimer containing equivalent and nonequivalent lithium atoms.) The observed ratio of 1.0630 for $\nu_{4}\left({ }^{6} \mathrm{Li}\right) / \nu_{4}\left({ }^{7} \mathrm{Li}\right)$ agrees quite well with the calculated ratio of 1.0594 from the product rule for this mode. The behavior of this absorption area upon warming the matrix and allowing diffusion to occur is identical to the bands at 626,646 , and 661 $\mathrm{cm}^{-1}$ and 537, 550, and $569 \mathrm{~cm}^{-1}$ which were previously assigned to the $\nu_{5}$ and $\nu_{6}$ species of the rhomboid dimer of ${ }^{7} \mathrm{Li}_{2} \mathrm{~F}_{2},{ }^{6} \mathrm{Li}^{7} \mathrm{LiF}_{2}$, and ${ }^{6} \mathrm{Li}_{2} \mathrm{~F}_{2}$ [2]. The three sets of features also exhibit the same relative intensity diminution relative to the monomeric species when spectra are observed in samples deposited from higher effusing temperatures.

The other set of bands in this region exhibit a different rate of disappearance on warming the matrix than those demonstrated by the features ascribed to the ring-shaped dimer. Also, the diminution in intensity of these bands, upon deposition from a higher 


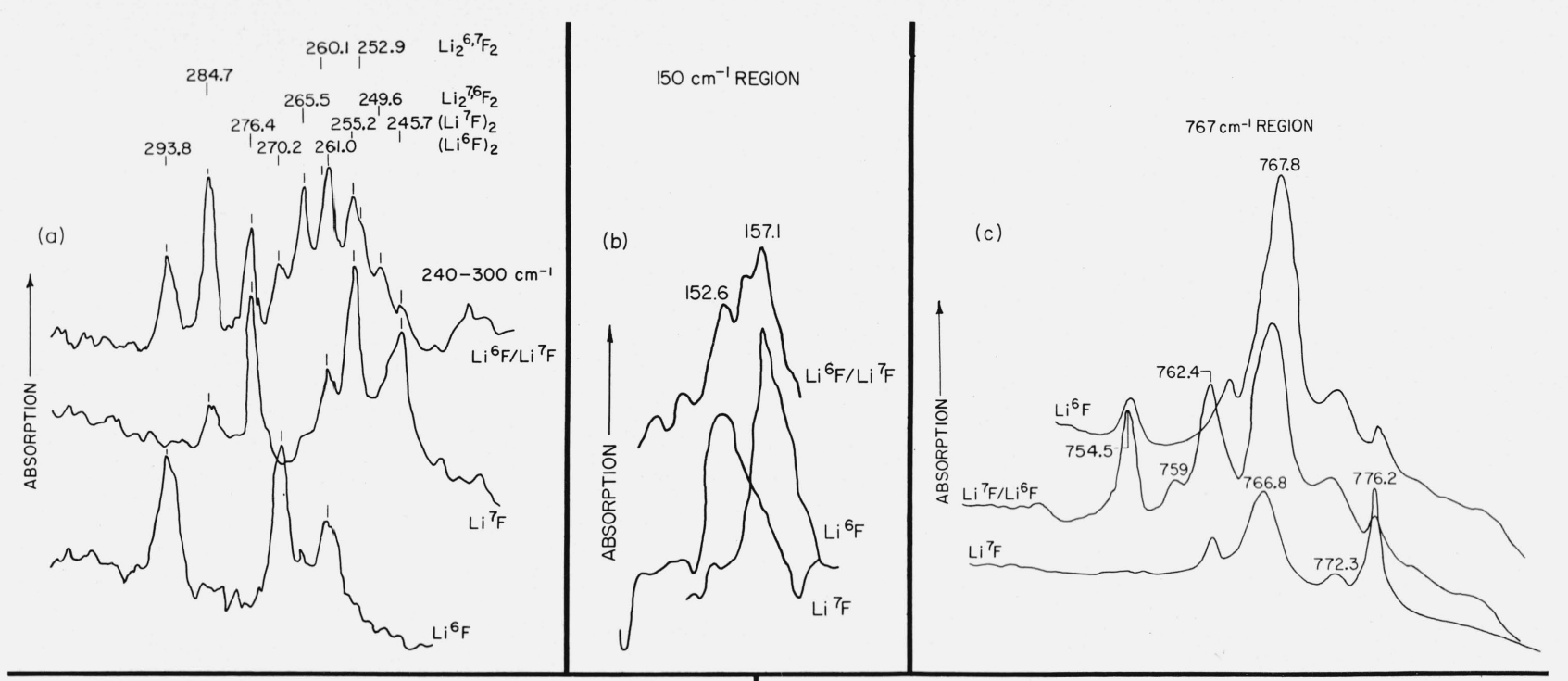

$720 \mathrm{~cm}^{-1}$ REGION
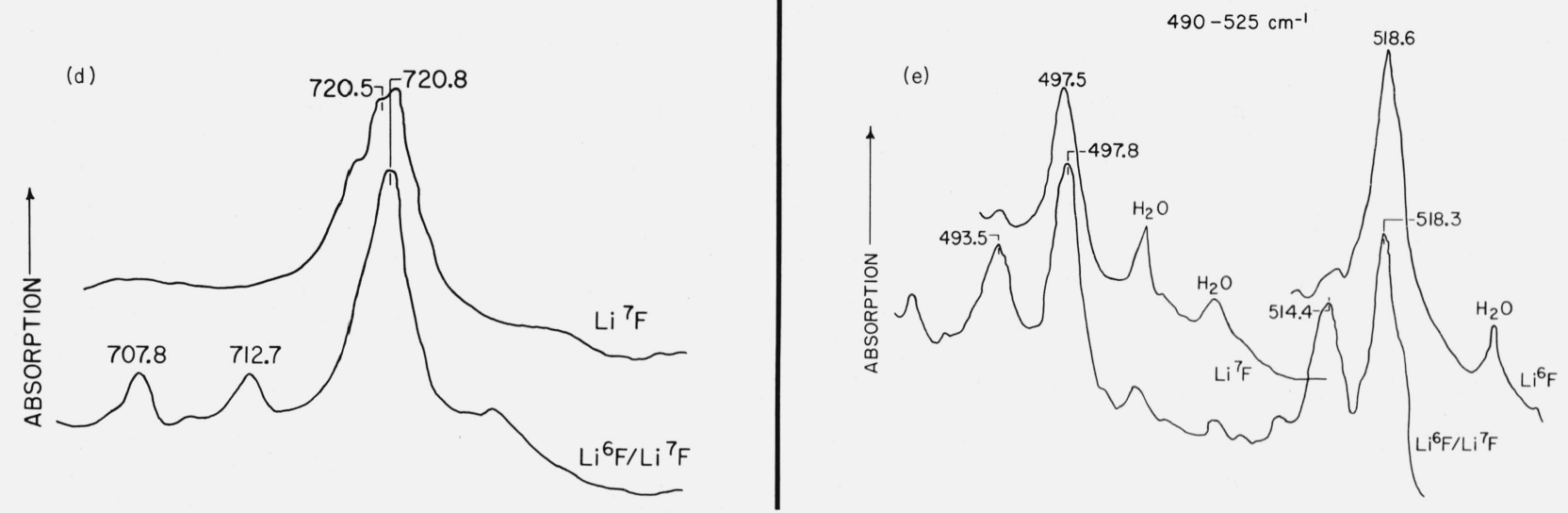

Figure 1. Infrared spectra of matrix isolated ${ }^{7} \mathrm{LiF},{ }^{6} \mathrm{LiF}$, and a $1: 1$ mixture of ${ }^{6} \mathrm{LiF} /{ }^{7} \mathrm{LiF}$.

$$
\begin{aligned}
& \text { (a) } 240-300 \mathrm{~cm}^{-1} \text { region } \\
& \text { (b) } 150 \mathrm{~cm}^{-1} \text { region } \\
& \text { (c) } 767 \mathrm{~cm}^{-1} \text { region } \\
& \text { (d) } 720 \mathrm{~cm}^{-1} \text { region } \\
& \text { (e) } 490-525 \mathrm{~cm}^{-1} \text { region }
\end{aligned}
$$

effusing temperature relative to the change in intensity of the monomeric species, is distinctly less than that observed for the ring-shaped dimer. These features occur at 270.2 and $261.0 \mathrm{~cm}^{-1}$ for ${ }^{6} \mathrm{LiF}$ and at 255.2 and $245.7 \mathrm{~cm}^{-1}$ for ${ }^{7} \mathrm{LiF}$. The spectrum of the isotopic mixture gives additional bands at 265.5, 260.1, 252.9 and $249.6 \mathrm{~cm}^{-1}$. These absorptions are assigned to the linear dimer species. Since the frequencies for the pure isotopic molecules are less than $10 \mathrm{~cm}^{-1}$ apart, the vibrations probably correspond to different symmetry representations; namely, the stretching $(\Sigma)$ and bending (П) modes of the dimer. Thus, we assign the bands at 255.2, 270.2, 265.5, and 260.1 to the $\nu_{3}$ vibrations, the lowest stretching mode, of $\mathrm{F}-{ }^{7} \mathrm{Li}-\mathrm{F}-{ }^{7} \mathrm{Li}$, $\mathrm{F}-{ }^{6} \mathrm{Li}-\mathrm{F}-6 \mathrm{Li}, \mathrm{F}-{ }^{7} \mathrm{Li}-\mathrm{F}-6 \mathrm{Li}$, and $\mathrm{F}^{-6} \mathrm{Li}-\mathrm{F}-{ }^{7} \mathrm{Li}$, respectively. The bands at $245.7,261.0,252.9$, and $249.6 \mathrm{~cm}^{-1}$ then correspond to the $\nu_{4}$ bending modes of $\mathrm{F}-{ }^{7} \mathrm{Li}-\mathrm{F}-$
${ }^{7} \mathrm{Li}, \mathrm{F}-{ }^{6} \mathrm{Li}-\mathrm{F}-{ }^{6} \mathrm{Li}, \mathrm{F}-{ }^{7} \mathrm{Li}-\mathrm{F}-{ }^{6} \mathrm{Li}, \mathrm{F}-{ }^{6} \mathrm{Li}-\mathrm{F}-{ }^{7} \mathrm{Li}$, respectively. The measurements reported were obtained under higher resolution conditions than those shown. In addition to trapping the species from the isotopic mixtures, thick deposits of the nearly pure isotopic samples, as well as 1:1 to 1:3 mixtures, were observed.

Arguments concerning the assignment based upon intensity considerations in this region are quite difficult. Particularly, there are bands in this region which are due to the polymeric or aggregate species containing more than two lithium atoms. Evidence for these bands is obtained from temperature cycling experiments in which the dimeric bands disappear and the polymeric bands increase in intensity. Also, for the pure ${ }^{6} \mathrm{Li}$ and ${ }^{7} \mathrm{Li}$ spectra, one notices absorptions in the wings of the bands (between 270.2 and 261.0 $\mathrm{cm}^{-1}$ in ${ }^{6} \mathrm{LiF}$ and 255.2 and 245.7 in ${ }^{7} \mathrm{LiF}$ ) that is due 
to the polymeric species. Therefore, a detailed intensity match with the expected 1:1:1:1 ratio for the mixed isotope is not possible in this region. Despite these difficulties, however, one observes qualitative agreement for the pairs of lines in the mixed isotope. Consider 265.5, $249.6 \mathrm{~cm}^{-1}$ for ${ }^{7,}{ }^{6} \mathrm{Li}_{2} \mathrm{~F}_{2}$ and 260.1, $252.9 \mathrm{~cm}^{-1}$ for ${ }^{6,}{ }^{7} \mathrm{Li}_{2} \mathrm{~F}_{2}$. These lines have roughly the same intensity ratio as the pairs of lines 270.2 , $261.0 \mathrm{~cm}^{-1}$ and $255.2,245.7 \mathrm{~cm}^{-1}$ for the pure species. (The buildup in intensity of the 261.0 and 260.1 peaks is due to their near coincidence.) Since the natural and enriched samples of the ${ }^{7} \mathrm{LiF}$ and ${ }^{6} \mathrm{LiF}$ contained about 5 percent of the other isotope, the thick deposits of the individual species gave features of the mixed isotope spectra with the appropriate intensity ratios.

Absorption bands at 152.8 and $157.1 \mathrm{~cm}^{-1}$ for the ${ }^{7} \mathrm{LiF}$ and ${ }^{6} \mathrm{LiF}$ samples presented the same behavior upon diffusion in the matrix and the same intensity diminution upon deposition from a higher temperature as the previous features assigned to the linear dimer. The spectrum appears in figure 1b. The mixed isotopic sample indicates a superposition of the spectra of the two pure samples. These bands are assigned to $\nu_{5}$ of the $\mathrm{F}^{-7} \mathrm{Li}-\mathrm{F}-{ }^{7} \mathrm{Li}$ and $\mathrm{F}^{-6} \mathrm{Li}-\mathrm{F}-{ }^{6} \mathrm{Li}$ species. It was not possible to resolve the spectrum for the mixture into the $\mathrm{F}-{ }^{6} \mathrm{Li}-\mathrm{F}-{ }^{7} \mathrm{Li}$ and $\mathrm{F}-{ }^{7} \mathrm{Li}-\mathrm{F}-{ }^{6} \mathrm{Li}$ components, although it appears clear from the normal coordinate analysis described below that the frequencies for $\nu_{5}$ of these mixed species are between about 152 and $157 \mathrm{~cm}^{-1}$.

Several other absorption features, both broad and narrow, were observed in the spectra of the pure and mixed isotopes. Their behavior upon diffusion, however, indicates that these bands arose from systems other than either the dimeric or monomeric species.

\subsection{The $900-400 \mathrm{~cm}^{-1}$ Region}

The absorption bands arising from the two stretching modes of a linear $\mathrm{Li}_{2} \mathrm{~F}_{2}$ molecule are expected in this region. The higher frequency stretching mode of $\mathrm{Li}_{2} \mathrm{~F}_{2}$ occurs at 767.8 and $720.5 \mathrm{~cm}^{-1}$ in ${ }^{6} \mathrm{Li}_{2} \mathrm{~F}_{2}$ and ${ }^{7} \mathrm{Li}_{2} \mathrm{~F}_{2}$. Spectra of these regions are given in figures lc and $1 \mathrm{~d}$. In addition to these features, one observes the two stretching modes $\nu_{5}$ and $\nu_{6}\left(\mathrm{~B}_{2 \mathrm{u}}\right.$ and $\left.\mathrm{B}_{3 \mathrm{u}}\right)$ of the rhomboid dimer, as well as the bands for the monomer. Although these features are not presented in the figures, the species occur at substantially the same frequencies as reported previously [1-5].

Features also appear which are attributed to species other than the monomer or either dimer. These bands increase in intensity upon diffusion which indicates that they are possibly due to a polymer of three or more LiF aggregates. No further discussion concerning the species responsible for these absorptions will be given here.

High resolution spectra of $1: 1$ mixtures of ${ }^{6} \mathrm{LiF} /{ }^{7} \mathrm{LiF}$ show the $767.8 \mathrm{~cm}^{-1}$ band split into two components of equal intensity. These correspond to $\nu_{1}$ of $\mathrm{F}-6 \mathrm{Li}-$ $\mathrm{F}-{ }^{6} \mathrm{Li}$ and $\mathrm{F}-{ }^{6} \mathrm{Li}-\mathrm{F}-{ }^{7} \mathrm{Li}$ at 767.8 and $766.8 \mathrm{~cm}^{-1}$. The approximate equality of intensities of these two components (in a $1: 1$ isotopic mixture) is expected and provides further evidence for a dimer with two nonequivalent lithium atoms. The corresponding absorption in ${ }^{7} \mathrm{LiF}$ is found at $720.5 \mathrm{~cm}^{-1}$. This band is complicated by a shoulder to the low frequency side which is more prominent in a 1:1 mixture of ${ }^{6} \mathrm{LiF} /$ ${ }^{7} \mathrm{LiF}$. Two weaker bands also were found in the mixed isotopic sample. These features, as shown by diffusion experiments, are not due to the linear dimeric form. Careful measurements of ${ }^{7} \mathrm{LiF}$ and various mixtures of ${ }^{6} \mathrm{LiF}$ and ${ }^{7} \mathrm{LiF}$ indicate that $\nu_{1}$ of $\mathrm{F}-{ }^{7} \mathrm{Li}-\mathrm{F}-{ }^{7} \mathrm{Li}$ is at $720.5 \mathrm{~cm}^{-1}$ while $\nu_{1}$ of $\mathrm{F}-7 \mathrm{Li}-\mathrm{F}-6 \mathrm{Li}$ is at $720.8 \mathrm{~cm}^{-1}$. The small isotope shifts for the $\nu_{1}$ and $\nu_{2}$ modes, as seen in the normal coordinate calculations, supports the existence of the linear dimer model.

Features attributed to the $\nu_{2}$ symmetric stretching mode of $\mathrm{F}-\mathrm{Li}-\mathrm{F}-\mathrm{Li}$ occur at 497.5 and $518.6 \mathrm{~cm}^{-1}$ in ${ }^{7} \mathrm{Li}_{2} \mathrm{~F}_{2}$ and ${ }^{6} \mathrm{Li}_{2} \mathrm{~F}_{2}$. The mixed isotopic spectra, given in figure le, show features at 493.5 and 514.4 $\mathrm{cm}^{-1}$ that are not due to any dimeric or monomeric species. These bands increase markedly in intensity upon diffusion and may be due to the same species responsible for the unassigned absorptions in the 768 and $721 \mathrm{~cm}^{-1}$ regions. Measurements of various mixed isotopic samples of ${ }^{7} \mathrm{LiF}$ and ${ }^{6} \mathrm{LiF}$ show $\nu_{2}$ of $\mathrm{F}-{ }^{6} \mathrm{Li}-$ $\mathrm{F}-7 \mathrm{Li}$ to be at $497.8 \mathrm{~cm}^{-1}$, while the corresponding frequency of $\mathrm{F}^{-7} \mathrm{Li}-\mathrm{F}-6 \mathrm{Li}$ is at $518.3 \mathrm{~cm}^{-1}$. In this region it was again useful to measure the spectrum of ${ }^{7} \mathrm{LiF}$ at 768 and $518 \mathrm{~cm}^{-1}$ and ${ }^{6} \mathrm{LiF}$ at 721 and $497 \mathrm{~cm}^{-1}$ with thick samples in order to obtain the mixed isotope spectrum in a 5 percent concentration. The sets of observed frequencies for the final assignment of the linear $\mathrm{Li}_{2} \mathrm{~F}_{2}$ molecule appear in tables 3 and 4 , along with the calculated frequencies from the normal coordinate analysis.

The absorption spectrum of monomeric ${ }^{7} \mathrm{LiF}$ in the argon matrix is shown in figure 2. The doublets ascribed to the fundamental modes of the diatomic LiF species are the only absorption bands in the spectrum which exhibit reversible temperature dependent behavior. As the temperature is raised from 20-33 K, the doublet is smeared out with an apparent blue shift of about $1 \mathrm{~cm}^{-1}$ for the low frequency

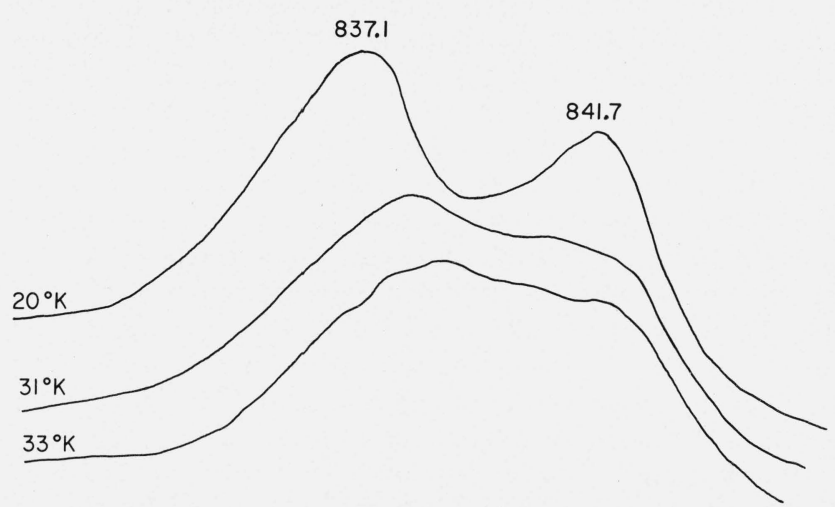

FigURE 2. Monomeric ${ }^{7} \mathrm{LiF}$ in $\mathrm{Ar}$ at various temperatures. 
component. No conclusion regarding the cause of this behavior will be given here, except to note that only the absorption bands attributed to monomeric ${ }^{6} \mathrm{LiF}$ and ${ }^{7} \mathrm{LiF}$ at 842 and $888 \mathrm{~cm}^{-1}$ exhibit such a phenomenon.

\section{Discussion}

In order to support the interpretation of a linear $\mathrm{Li}_{2} \mathrm{~F}_{2}$ dimeric species, we performed a normal coordinate analysis for the four isotopic systems. Several models for the linear structure were considered; namely, a $\mathrm{F}-\mathrm{Li}-\mathrm{F}-\mathrm{Li}$ dimer in which all bonds were equivalent, a $\mathrm{F}-\mathrm{Li}-\mathrm{F} \cdot \mathrm{Li}$ dimer with a bifluoride structure, and a species $\mathrm{F}-\mathrm{Li} \cdots \mathrm{F}-\mathrm{Li}$ containing an elongated central bond. For the normal LiF bonds of the model structures, a length of $1.51 \AA$ from the gas phase was assumed, while a value of $2.01 \AA$ from crystalline LiF was taken for the long bonds [9]. The force field for a chosen model was first refined about the ${ }^{6} \mathrm{Li}$ and ${ }^{7} \mathrm{Li}$ isotopic species. Interaction force constants were systematically varied until close fits to the observed frequencies were attained. This force field was then used to calculate the frequencies for the mixed isotopic species, namely, the $\mathrm{F}-{ }^{6} \mathrm{Li}-\mathrm{F}-{ }^{7} \mathrm{Li}$ and $\mathrm{F}^{-7} \mathrm{Li}-\mathrm{F}-{ }^{6} \mathrm{Li}$ molecules. In view of the assumptions concerning the bond lengths and interactions in the force constant matrix, the significance of the force field is limited. Consequently, rather than stressing the values of the individual force constants, recognizing that the force field is not unique, we prefer to emphasize the closeness of the frequency fit for the four isotopic molecules as evidence favoring the linear dimeric structure.

For a linear dimer, $\mathrm{F}-\mathrm{Li}-\mathrm{F}-\mathrm{Li}$ of $C_{\infty v}$ symmetry, the vibrational representation is $\Gamma_{v}=3 \Sigma^{+}+2 \Pi$, with the stretching vibrations occurring in the $\Sigma^{+}$species and the bending modes conforming to $\Pi$ symmetry. The vibrational problem was cast in terms of the internal coordinates and force constant matrix that appear in table 1. Familiar $G F$ matrix methods were used in solving the vibrational secular equation.

TABLE 1. Internal coordinates and force constant matrix for the linear $\mathrm{Li}_{2} \mathrm{~F}_{2}$ dimer.

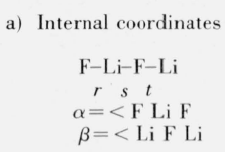

b) Force constant matrix

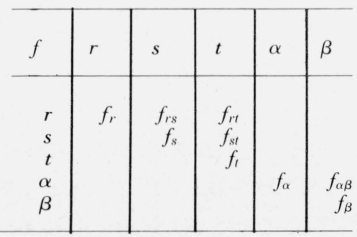

Since the elements of the $G$ matrix for the stretching vibrations are independent of bond length, the frequency fits for the $\Sigma^{+}$species of the three linear dimers are equivalent. The force constants for the various stretching force constants and the comparison between the observed and calculated frequencies appear in tables 2 and 3, respectively. Again, the force constants were refined about only the ${ }^{6} \mathrm{Li}_{2} \mathrm{~F}_{2}$ and ${ }^{7} \mathrm{Li}_{2} \mathrm{~F}_{2}$ isotopes. The frequencies for the mixed isotopes are determined from this potential function. Since a unique potential function probably cannot be determined from the frequency data alone in this manner, it is not worthwhile to refine the force field over all isotopes. The results of the normal coordinate calculation for the $\Pi$ species appear in table 4 . For these vibrations, the change in geometry affects the calculated frequencies. Table 4 indicates, however, that a distinction in geometry cannot be made decisively for the $\Pi$ species since the frequency fits are quite reasonable for the three models.

TABLE 2. Summary of force constants for the linear dimer models of $\mathrm{Li}_{2} \mathrm{~F}_{2}$. The stretching force constants are in units of millidynes per angstrom, while the bending force constants are in units of millidynes $\cdot$ angstroms

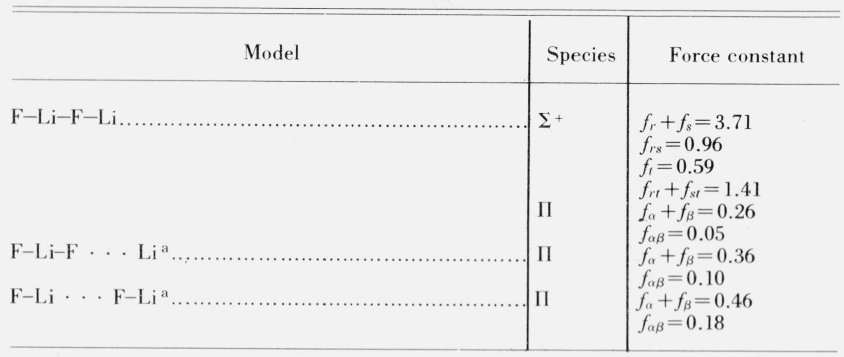

${ }^{a}$ A dotted line represents a longer bond distance.

TABLE 3. Comparison between the observed and calculated frequencies, in $\mathrm{cm}^{-1}$, for the $\Sigma^{+}$symmetry species of the linear $\mathrm{Li}_{2} \mathrm{~F}_{2}$ dimer.

\begin{tabular}{|c|c|c|c|c|c|c|}
\hline & Obs & Calc & $\Delta \nu$ & Obs & Calc & $\Delta \nu$ \\
\hline & \multicolumn{2}{|c|}{$\mathrm{F}^{6} \mathrm{LiF}^{6} \mathrm{Li}$} & & \multicolumn{2}{|c|}{$\mathrm{F}^{7} \mathrm{LiF}^{7} \mathrm{Li}$} & \\
\hline$\nu_{1}$ & 767.8 & 768.0 & +0.2 & 720.5 & 720.3 & -0.2 \\
\hline$\nu_{2}$ & 518.6 & 518.8 & +0.2 & 497.5 & 498.2 & +0.7 \\
\hline \multirow[t]{2}{*}{$\begin{array}{l}\nu_{2} \\
\nu_{3}\end{array}$} & 270.2 & 266.5 & -3.7 & 255.2 & 258.7 & +3.5 \\
\hline & \multicolumn{2}{|c|}{$\mathrm{F}^{6} \mathrm{LiF}^{7} \mathrm{Li}$} & & \multicolumn{2}{|c|}{$\mathrm{F}^{7} \mathrm{LiF}^{6} \mathrm{Li}$} & \\
\hline$\nu_{1}$ & 766.8 & 767.7 & +0.9 & 720.8 & 720.8 & \\
\hline$\nu_{2}$ & 497.8 & 499.5 & +1.7 & 518.3 & 517.2 & -1.1 \\
\hline$\nu_{3}$ & 260.1 & 258.9 & -1.2 & 265.5 & 266.3 & -0.8 \\
\hline
\end{tabular}

Although rather drastic approximations enter the force field calculation, we can make several observations concerning the various possibilities for a linear model. The plausibility of the bifluoride structure suggests that $f_{r}=f_{s}$ and $f_{r t}=0$. The results of this computation yield values of $f_{r}=1.8 \mathrm{mdyn} / \AA, f_{t}=0.24$ $\operatorname{mdyn} / \AA$, and $f_{r r}=0.91 \mathrm{mdyn} / \AA$. Although the interaction force constant is rather large, the values are 
TABLE 4. Comparison between the observed and calculated frequencies, in $\mathrm{cm}^{-1}$, for the П symmetry species of three models for the $\mathrm{Li}_{2} \mathrm{~F}_{2}$ linear dimer.

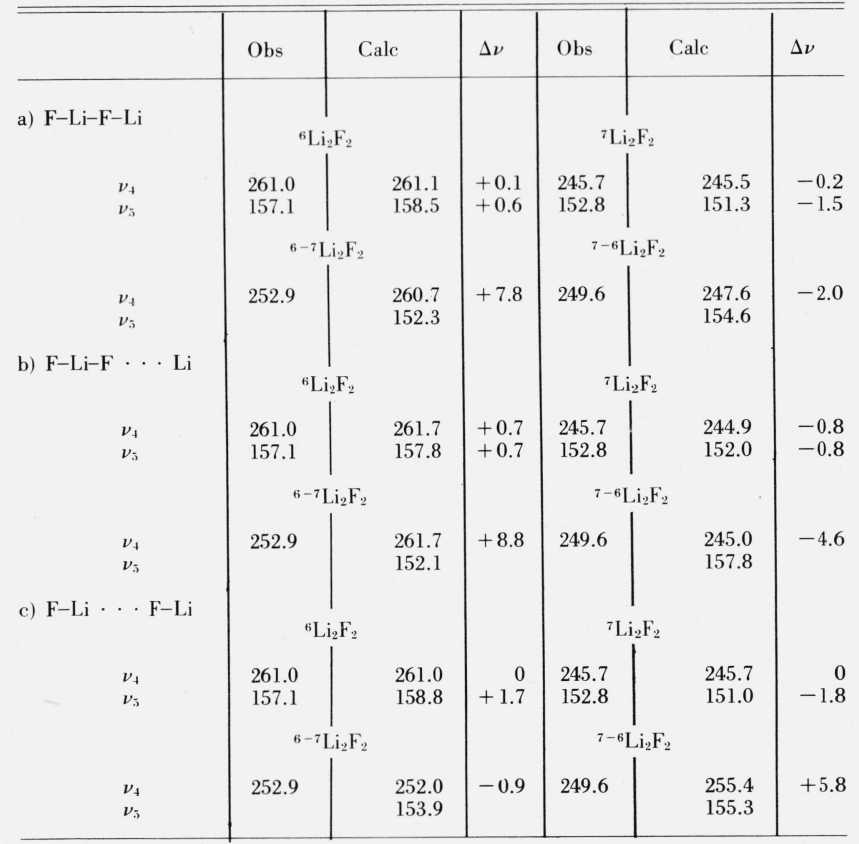

not unreasonable. The frequency fits for the ${ }^{6} \mathrm{Li}_{2} \mathrm{~F}_{2}$ and ${ }^{7} \mathrm{Li}_{2} \mathrm{~F}_{2}$ are approximately $1 \mathrm{~cm}^{-1}$, except for $\nu_{2}$ which is about $11 \mathrm{~cm}^{-1}$. Including another interaction force constant, however, in the combinational form of $f_{s t}+f_{r t}$, we reduce the error in the frequency fit to well within $1 \mathrm{~cm}^{-1}$ for the pure 6 and 7 species, except for $\nu_{3}$, which is about $3.5 \mathrm{~cm}^{-1}$ from the observed value. This frequency fit is tabulated in table 3 for all the isotopic species. The values for the diagonal force constants in this case are $f_{r}=f_{s}=1.85 \mathrm{mdyn} / \AA$ and $f_{t}=0.6 \mathrm{mdyn} / \mathrm{A}$. Again, the interaction force constants are relatively large; namely, $f_{r s}=0.96$ mdyn $/ \AA$ and the linear combination of $f_{s t}+f_{r t}=1.41$ mdyn/A. The refinement of the force constants about the observed frequencies depends upon a least squares method; however, the number of known data is not great enough to make a statistical analysis of the force constants profitable. Since additional molecular information, as for example, rotational distortion data or mean-square amplitude data for the gas phase species, is required to further characterize the force field, other sets of force constants may exist which fit the data. Summarizing, we wish to stress that the probable nonuniqueness of the force field precludes a choice of structures on the basis of individual values of the force constants. The close frequency fit determined from the modified potential function, however, strongly indicates the linear nature of the trapped species.

Approximate descriptions of the stretching $\Sigma^{+}$ modes for the ${ }^{7} \mathrm{LiF}$ and ${ }^{6} \mathrm{LiF}$ species are defined by the calculated normal coordinate vectors. The highest frequency $\nu_{1}$ appears to be mainly a $\mathrm{F}-\mathrm{Li}-\mathrm{F}$ out-of- phase stretching mode, while the $\nu_{3}$ vibration is composed primarily of the $\mathrm{Li}-\mathrm{F}-\mathrm{Li}$ out-of-phase motion. The $\nu_{2}$ vibration is approximately a $\mathrm{F}-\mathrm{Li}$, F-Li symmetric stretching motion. Since it is not clear which linear dimer model is preferred, detailed descriptions of the bending modes are not given.

A further problem arises in the assignment of the $\nu_{3}$ and $\nu_{4}$ vibrations to the $\Sigma^{+}$and $\Pi$ species, respectively, since the assignment may reasonably be reversed. A choice cannot be made on the basis of the product rule. For example, the assignment presented in table 3 for ${ }^{6} \mathrm{Li}_{2} \mathrm{~F}_{2}$ and ${ }^{7} \mathrm{Li}_{2} \mathrm{~F}_{2}$ gives an isotopic frequency ratio of 1.176 for $\nu_{1} \nu_{2} \nu_{3} / \nu_{1}^{\prime} \nu_{2}^{\prime} \nu_{3}^{\prime}$, which is compared to a calculated value of 1.144 from the product rule. Reversing the assignments for the stretching and bending modes, $\nu_{3}$ and $\nu_{4}$, respectively, gives an isotopic frequency value of 1.180. Table 5 presents the frequency fit for the bifluoride model, as an example, for an assignment with the two frequencies reversed. As before, the force field that was refined about the ${ }^{6} \mathrm{Li}_{2} \mathrm{~F}_{2}$ and ${ }^{7} \mathrm{Li}_{2} \mathrm{~F}_{2}$ isotopic frequencies was used to calculate the frequencies for the mixed species. The fit for the reversed frequency assignment is only slightly worse than the fit in tables 3 and 4 . Although it is difficult to resolve the choice definitely, we prefer the assignment with the stretching motion at the higher frequency.

TABLE 5. Comparison between the observed and calculated frequencies, in $\mathrm{cm}^{-1}$, for the bifluoride structure of the $\mathrm{Li}_{2} \mathrm{~F}_{2}$ linear dimer. The $\nu_{3}$ and $\nu_{4}$ frequencies are reversed from the assignment presented in tables 3 and 4.

\begin{tabular}{|c|c|c|c|c|c|c|}
\hline & Obs & Calc & $\Delta \nu$ & Obs & Calc & $\Delta \nu$ \\
\hline & \multicolumn{2}{|c|}{${ }^{6} \mathrm{Li}_{2} \mathrm{~F}_{2}$} & & \multicolumn{2}{|c|}{${ }^{7} \mathrm{Li}_{2} \mathrm{~F}_{2}$} & \\
\hline$\nu_{1}$ & 767.8 & 768.0 & 0.2 & 720.5 & 720.3 & -0.2 \\
\hline$\nu_{2}$ & 518.6 & 518.1 & -.5 & 497.5 & 498.5 & 1.0 \\
\hline$\nu_{3}$ & 261.0 & 257.3 & -3.7 & 245.7 & 249.3 & 4.6 \\
\hline$\nu_{4}$ & 270.2 & 271.3 & 1.1 & 255.2 & 254.1 & -1.1 \\
\hline$\nu_{\bar{s}}$ & 157.1 & 157.9 & 0.8 & 152.8 & 151.9 & -0.9 \\
\hline & \multicolumn{2}{|c|}{${ }^{6-7} \mathrm{Li}_{2} \mathrm{~F}_{2}$} & & \multicolumn{2}{|c|}{${ }^{7-6} \mathrm{Li}_{2} \mathrm{~F}_{2}$} & \\
\hline$\nu_{1}$ & 766.8 & 767.7 & 0.9 & 720.8 & 720.7 & -0.1 \\
\hline$\nu_{2}$ & 497.8 & 499.8 & 2.8 & 518.3 & 516.6 & -1.7 \\
\hline$\nu_{3}$ & 252.9 & 249.5 & -3.4 & 265.5 & 257.1 & -8.5 \\
\hline$\nu_{4}$ & 260.1 & 271.2 & 11.1 & 249.6 & 254.0 & 4.4 \\
\hline$\nu_{\tilde{j}}$ & & 152.1 & & & 157.7 & \\
\hline
\end{tabular}

The observed product rule for the pure species is also consistent with a $D_{3 h}$ cyclic structure for the trimer. If one assigns $767.8,518.6$, and $261.0 \mathrm{~cm}^{-1}$ to ${ }^{7} \mathrm{Li}_{3} \mathrm{~F}_{3}$ and $720.8,497.5$, and $245.7 \mathrm{~cm}^{-1}$ to ${ }^{6} \mathrm{Li}_{3} \mathrm{~F}_{3}$, the product rule predicts a value of 1.158 for the $E^{\prime}$ modes as compared to an observed value of 1.180 . The infrared active bending modes $\left(A_{2}^{\prime \prime}\right)$ could then be satisfactorily assigned to $270.2,265.5,260.1$, and 255.2 for ${ }^{6} \mathrm{Li}_{3} \mathrm{~F}_{3},{ }^{6} \mathrm{Li}_{2}{ }^{7} \mathrm{LiF}_{3},{ }^{6} \mathrm{Li}^{7} \mathrm{Li}_{2} \mathrm{~F}_{3}$, and ${ }^{7} \mathrm{Li}_{3} \mathrm{~F}_{3}$, respectively. This assignment leaves the far infrared bands at 152-157 $\mathrm{cm}^{-1}$ unassigned. It also does not explain the intensity results obtained for the 767.8 and 766.8 $\mathrm{cm}^{-1}$ bands nor the intensity ratios obtained by 
running ${ }^{6} \mathrm{LiF}$ in the region of ${ }^{7} \mathrm{LiF}$ and vice versa. It is, perhaps, interesting to note that any breakdown in symmetry due to site group splitting to $D_{3}$ or $C_{3}$ symmetry will not affect the number of expected bands, since $E^{\prime}$ of $D_{3 h}$ maps onto $E$ in both $D_{3}$ and $C_{3}$ groups, while $A_{2}^{\prime \prime}$ maps onto $A_{2}$ and $A$, respectively. Assignment of these features to a cyclic trimer of lithium fluoride is also inconsistent with the vibrational data in the 770 and $500 \mathrm{~cm}^{-1}$ regions for the mixed species. In particular, it is hard to envision a molecule of this symmetry experiencing such small isotope shifts for stretching modes; that is, the cyclic model would require an isotope shift for the $E^{\prime}$ stretching modes of ${ }^{7} \mathrm{Li}_{3} \mathrm{~F}_{3}$ and ${ }^{7} \mathrm{Li}_{2}{ }^{6} \mathrm{LiF}_{3}$ to be of the order of one $\mathrm{cm}^{-1}$.

The evidence then for a linear dimer of lithium fluoride can be briefly summarized as follows. Using double boiler and diffusion experiments, five absorption bands are shown to belong to the same molecular species. The expected intensity is found in the 767.8 and $766.8 \mathrm{~cm}^{-1}$ bands of ${ }^{6} \mathrm{Li}_{2} \mathrm{~F}_{2}$ and the ${ }^{6} \mathrm{Li}^{7} \mathrm{LiF}_{2}$ isotopic variants of the proposed dimers. The TellerRedlich product rule for the proposed assignment is 1.176 for the $\Sigma$ modes. If one reverses the assignment for $\nu_{3}$ and $\nu_{4}$, the product rule calculation yields 1.180. Both of these product rule values are consistent with the calculated value of 1.144 . (While this agreement is a necessary prerequisite for the proposed structure, product rule calculations are not sufficient proofs.) Examining the spectrum of ${ }^{\mathrm{n}} \mathrm{LiF}$ and ${ }^{6} \mathrm{LiF}$ (95 percent enriched) in regions of ${ }^{6} \mathrm{LiF}$ and ${ }^{7} \mathrm{LiF}$, respectively, in rather heavy deposits, one observes the spectrum of the mixed isotope (in a 5 percent concentration) that is consistent with a linear dimer model. Finally, an empirical force field determined fr. $m{ }^{6} \mathrm{Li}_{2} \mathrm{~F}_{2}$ and ${ }^{7} \mathrm{Li}_{2} \mathrm{~F}_{2}$ predicts quite well the observed $v$ siational spectrum for the two mixed isotopic linear species.

Some of us (S. A. and N. A.) wish to acknowledge the support of the Propilsion Division of the Air Force Office of Scientific Research, U.S. Department of Defense.

\section{References}

[1] Linevsky, M. J., J. Chem. Phys. 34, 587 (1961).

[2] Linevsky, M. J., J. Chem. Phys. 38, 658 (1963).

[3] Snelson, A., and Pitzer, K. S., J. Phys. Chem. 67, 882 (1963).

[4] Schlick, S., and Schnepp, O., J. Chem. Phys. 41, 463 (1964).

[5] Reddington, R. L., J. Chem. Phys. 44, 1238 (1966).

[6] Snelson, A., J. Chem. Phys. 46,3652 (1967).

[7] Mann, D. E., Calder, G. V., Seshadri, K. S., White, D., and Linevsky, M. J., J. Chem. Phys. 46, 1138 (1967).

[8] Certain commercial instruments are identified in this paper to specify completely the experimental procedure. In no case does such identification imply a recommendation or endorsement by the National Bureau of Standards or the National Institutes of Health.

[9] Tables of Interatomic Distances and Configuration in Molecules and Ions, Sutton, L. E., Ed. (The Chemical Society, London, 1958).

1101 Wilson, E. B., Decius, J. C., and Cross, P. C., Molecular Vibrations (McGraw-Hill Book Co., Inc., New York, 1955).

(Paper 72A5-516) 